\title{
Relationship between obstructive sleep apnoea, driving simulator performance, and risk of road traffic accidents
}

\author{
P M Turkington, M Sircar, V Allgar, M W Elliott
}

\begin{abstract}
Background-Obstructive sleep apnoea (OSA) has been shown to be associated with an increased risk of road traffic accidents (RTAs). Predicting the driving ability and risk of RTAs in an individual with OSA is difficult. On-road testing is the gold standard, but this is time consuming, expensive, and potentially dangerous. Simple computer based driving simulators have been developed to help determine driving ability. Although patients with OSA have been shown to perform poorly compared with matched controls, it is not known whether these simulators can predict those at most risk of accidents. In this study we evaluated whether data derived from a simple driving simulator provided information over and above that obtained from the history and a sleep study that might be useful for advising patients about driving.
\end{abstract}

Methods-We examined 150 patients admitted for routine sleep studies for investigation of OSA and snoring. Each patient performed a 20 minute driving simulation and completed a questionnaire regarding their driving history and experience.

Results-Logistic regression analysis was used to investigate factors associated with patients' performance on the simulator. It was found that patient characteristics, older age (OR 1.05 , 95\% CI 1.01 to 1.09 , p<0.01), female sex (OR 9.32, 95\% CI 1.09 to $79.4, p<0.04)$, and self-reported alcohol consumption (OR 1.04, 95\% CI 1.01 to $1.07, p<0.01)$ had the greatest influence; however, the number of self-reported near miss accidents was independently associated with a poor performance (OR 2.62, $95 \%$ CI 1.00 to $6.88, p<0.05)$. A further logistic regression was used to investigate whether clinical history, sleep study results, and data from the driving simulator were useful in classifying patients with OSA as having had an RTA. The number of off-road events per hour on the simulator was independently associated with a history of previous RTA (OR $1.004,95 \%$ CI 1.0004 to $1.008, p<0.03)$. The Epworth score was independently associated with episodes of falling asleep at the wheel (OR $1.21,95 \%$ CI 1.12 to $1.31, p<0.00001)$ and near miss accidents (OR 1.15, 95\% CI 1.07 to $1.23, \mathrm{p}<0.0001)$. Using this model, $100 \%$ of patients who did not have an accident could be identified, but only $10 \%$ of those who did.

Conclusions-Although factors not directly related to OSA influence performance on a driving simulator, there is an independent relationship between driving ability in patients with OSA and performance on a simple computer based simulator. When combined with clinical history, it is those not reporting hypersomnolence and not having off-road events on the simulator who appear to be at least risk of adverse driving events. Poor performance on the simulator, however, relates poorly to accident history. These data require confirmation in future studies before simple computer simulators can be used in clinical practice to advise whether an individual is safe to drive.

(Thorax 2001;56:800-805)

Keywords: obstructive sleep apnoea; road traffic accidents; driving simulator

Obstructive sleep apnoea (OSA) is a common condition leading to sleep fragmentation and daytime hypersomnolence. ${ }^{1-3}$ It has been found to be associated with a significantly increased frequency of falling asleep at the wheel, ${ }^{3}$ increased risk of road traffic accidents (RTAs) ${ }^{4-8}$ and a higher incidence of near miss events while driving. ${ }^{9-11}$ Although some studies have shown that these events are more likely with more severe OSA, ${ }^{12-15}$ others have shown that prediction of increased risk of RTAs from clinical and physiological markers of OSA is poor, ${ }^{8}{ }^{16}$ making assessment of an individual's driving ability difficult. ${ }^{13-15}{ }^{17}$ The likelihood of having an accident does not relate to perceived sleepiness and this is of particular concern when assessing the safety of an individual to drive. ${ }^{17}$

Driving is an essential part of everyday life for most people and the withholding of a driving licence has major implications for employment and social functioning. Road testing is the gold standard but is time consuming, expensive, and potentially hazardous. Complex simulators which reproduce "real" driving are very expensive and not widely available. Simple simulators based around a PC have been developed to assess the driving skill of patients with OSA; these measure an individual's ability to track and maintain attention, two key components of driving. ${ }^{18}$ Poor performance on such simulators, comparable to the effect of driving with a blood alcohol concentration 
above the legal limit, has been reported in patients with OSA. ${ }^{16}{ }^{19-21}$ Performance ${ }^{19} 20$ has been shown to improve after treatment with continuous positive airway pressure (CPAP) ${ }^{20}{ }^{22-25}$ but it is not known whether this translates into safer driving. Although performance on a simple simulator is worse in patients with OSA than in normal controls, there is a considerable overlap ${ }^{18}$; some patients with severe OSA perform well whereas others with milder disease perform poorly.

The aim of this study was to determine the relationship between performance on a simple, cheap, easily used driving simulator, patient symptoms, sleep study results, and driving history to establish whether the additional information available from the simulator, in combination with the history and data derived from the sleep study, might help in advising patients about their ability to drive safely.

\section{Methods}

SUBJECTS

All patients undergoing sleep studies as part of the investigation of suspected snoring or sleep apnoea between November 1999 and May 2000 at St James's University Hospital were asked to participate in the study. The study protocol was approved by the local ethics committee. All patients recruited for the study were asked to complete a questionnaire regarding their previous driving history; this included any accidents (regardless of blame), near miss accidents, or episodes of nodding off at the wheel in the previous 1-3 years. Information on driving experience (miles per year and number of years since driving test passed), alcohol intake, and coffee intake were also obtained. A brief clinical history was taken and the Epworth score $^{26}$ recorded.

DRIVING SIMULATION

All subjects performed a 20 minute divided attention driving simulation test (DADS) after a 5 minute practice session using a commercially available simulator (SimDrive Divided Attention Driving Simulator, Stowood Scientific Instruments, Oxford, UK). All driving simulation tests were performed in the evening between 20.00 hours and 22.00 hours to prevent any potential fluctuations in performance associated with time of day. The object of the test was to steer an image of a car bonnet down the centre of a winding road as accurately as possible (measuring the ability to track) using a standard computer game steering wheel (Grandprix 1, Thrustmaster, USA). The test automatically stopped if the car was off the road for 15 seconds. During the test single digits, which changed randomly, were displayed at each corner of the computer screen. To test vigilance and reaction time the subjects were required to identify the number " 2 " when it appeared by pressing a button on the same side of the steering wheel as it appeared on the screen. Inclusion of this visual search requirement produced a divided attention task. The results of the DADS test were expressed as tracking error (standard deviation from the centre of the road), reaction time (average time to respond to target number), and number of off-road events per hour.

\section{SLEEP STUDY}

All patients underwent a limited sleep study between 23.00 hours and 07.00 hours using either the Autoset Clinical 1 (ResMed (UK), Abingdon, Oxon) or the Densa DMS2000 (Ferraris Medical Ltd, Enfield, UK). The Densa DMS2000 records oronasal airflow (thermistors), oxygen saturation, snoring (microphone), thoracic and abdominal respiratory effort (strain gauges), and heart rate (ECG). The Autoset Clinical 1 detects apnoeas, hypopnoeas, and inspiratory flow limitation through a flow sensor attached to the patient with nasal cannulae. The results of the study were subsequently interpreted using standard criteria with the respiratory disturbance index (RDI) expressed per hour of study.

\section{ANALYSIS OF DATA}

Statistical analysis of all data was performed with sPSs version 9.0 for Windows. Patient demographic and sleep study data are expressed as mean (SD). However, driving simulator data did not approximate to a normal distribution and were expressed as median and interquartile range (IQR). Logistic regression analysis was used to determine the relationship of a poor performance on the driving simulator with the number of self-reported adverse driving events in 1 and 3 years. A poor performance on the driving simulator was defined, in turn, as tracking error $>0.2$, reaction time $>2$ seconds, and number of off-road events $>10$ / hour. ${ }^{18} 252728$ Further logistic regression analysis was performed to determine whether having had at least one adverse driving event could be identified by driving simulator performance, sleep study results, and patient characteristics. A $p$ value of $<0.05$ was considered to indicate statistical significance.

\section{Results}

During the data collection period 366 sleep studies were booked. Of these, 25 patients did not attend, 95 were attending for a second study (usually a CPAP titration study) and were therefore excluded, and 96 patients refused consent to participate, leaving 150 patients in the study. The demographic data of these patients are shown in table 1 and indicate that they were representative of all patients undergoing sleep studies over the 6 month period. Eighty percent had an RDI of $>15 /$ hour or an Epworth score greater than 12;25\% reported an accident, 35\% a near miss event, and $15 \%$ reported nodding off at the wheel in the previous 3 years; $8 \%$ of the subjects took sleeping tablets, $46 \%$ drank more than three cups of coffee per day, and the median (IQR) amount of alcohol consumed per week was 8 (2-16) units. The mean (SD) age of passing the driving test was 21.5 (7.6) years, $55 \%$ drove more than 10000 miles per year, and 15\% classified themselves as a professional driver. 
Table 1 Demographic data of subjects and comparison with all patients attending for sleep studies during study period

\begin{tabular}{llll}
\hline & & $\begin{array}{l}\text { All patients attending } \\
\text { for sleep studies in } 6 \\
\text { month period }\end{array}$ & p value \\
\hline Age (years) & $49.8(10.7)$ & $45(21)$ & $0.39(\mathrm{NS})$ \\
Sex $(\% \mathrm{men})$ & $82.7^{\star \star}$ & $81.9^{\star \star}$ & $0.25(\mathrm{NS})$ \\
BMI $\left(\mathrm{kg} / \mathrm{m}^{2}\right)$ & $32.9(6.9)$ & $32.9(8.7)$ & $0.81(\mathrm{NS})$ \\
RDI (events/h) & $26.1(26.3)$ & $21(23.4)$ & $0.12(\mathrm{NS})$ \\
Epworth score & $12(7-17)^{\star \star \star}$ & $13(8-16)^{\star \star \star}$ & $0.39(\mathrm{NS})$ \\
Neck circumference $(\mathrm{cm})$ & $43.6(5)$ & $43.3(4.9)$ & $0.71(\mathrm{NS})$ \\
\hline
\end{tabular}

$\mathrm{BMI}=$ body mass index; $\mathrm{RDI}=$ respiratory disturbance index

${ }^{\star}$ All values are mean (SD) except ${ }^{\star \star}$ which are percentage and ${ }^{\star \star \star}$ which are median (IQR).

Table 2 Logistic regression analysis of poor tracking error on the driving simulator (only significant variables are shown)

\begin{tabular}{lllllll}
\hline Variable & $B$ & Wald test & p value & $\begin{array}{l}\text { Odds } \\
\text { ratio }\end{array}$ & $\begin{array}{l}\text { Lower } 95 \% \\
\text { CI }\end{array}$ & $\begin{array}{l}\text { Upper 95\% } \\
\text { CI }\end{array}$ \\
\hline Alcohol & 0.0377 & 6.29 & $<0.01$ & 1.04 & 1.01 & 1.07 \\
Age & 0.049 & 6.17 & $<0.01$ & 1.05 & 1.01 & 1.09 \\
Sex (female) & 2.232 & 4.16 & $<0.04$ & $9.32^{\star \star}$ & $1.09^{\star \star}$ & $79.4^{\star \star}$ \\
Near miss accidents & 0.9628 & 3.82 & $<0.05$ & 2.62 & 1.00 & 6.88
\end{tabular}

${ }^{\star}$ OR for every 1 unit increase in variable (i.e. estimated risk of poor performance on simulator increases by 2.62 for every additional near miss accident reported) except ${ }^{\star \star}$ which represents the estimated increased risk of women compared with men.

Table 3 Logistic regression analysis for number of off-road events on the driving simulator (only significant variables are shown)

\begin{tabular}{lllllll}
\hline Variable & $B$ & Wald test & p value & $\begin{array}{l}\text { Odds } \\
\text { ratio }\end{array}$ & $\begin{array}{l}\text { Lower } 95 \% \\
C I^{\star}\end{array}$ & $\begin{array}{l}\text { Upper } 95 \% \\
C^{\star}\end{array}$ \\
\hline Sex (female) & 1.96 & 9.28 & $<0.002$ & $7.1^{\star \star}$ & $2.01^{\star \star}$ & $25.1^{\star \star}$ \\
Age & 0.05 & 7.30 & $<0.007$ & 1.05 & 1.01 & 1.09 \\
Near miss accidents & 0.80 & 4.16 & $<0.04$ & 2.2 & 1.03 & 4.8 \\
\hline
\end{tabular}

${ }^{\star} \mathrm{OR}$ for every 1 unit increase in variable (i.e. estimated risk of poor performance on the simulator increases by 2.2 for every additional near miss accident reported) except ${ }^{\star \star}$ which represents the estimated increased risk of women compared with men.

Table 4 Logistic regression analysis for accidents in the previous year

\begin{tabular}{lllllll}
\hline Variable & \multirow{3}{*}{$\begin{array}{l}\text { Wald } \\
\text { score }\end{array}$} & p value & Odds ratio & $\begin{array}{l}\text { Lower } 95 \% \\
\text { CI }\end{array}$ & $\begin{array}{l}\text { Upper } 95 \% \\
\text { CI }\end{array}$ \\
\hline Off-road events/h & 0.004 & 3.37 & $<0.03$ & 1.004 & 1.0004 & 1.008 \\
Tracking error & 0.09 & 0.03 & $>0.05$ & 1.1 & 0.79 & 1.53 \\
Reaction time & 0.1 & 0.5 & $>0.05$ & 1.1 & 0.83 & 1.5 \\
Epworth score & 0.08 & 2.02 & $>0.05$ & 1.09 & 0.97 & 1.22 \\
RDI & 0.006 & 0.26 & $>0.05$ & 1.006 & 0.98 & 1.03 \\
\hline
\end{tabular}

$\mathrm{RDI}=$ respiratory disturbance index

${ }^{\star} \mathrm{OR}$ for every 1 unit increase in variable (i.e. estimated risk of road traffic accident increases by 1.004 or $0.4 \%$ for every additional off-road event on the simulator).

The driving simulator results revealed a median (IQR) tracking error of $0.321(0.218$ $1.172)$, response time of 2.85 (1.99-4.23) seconds, and number of off-road events per hour of $24(3-104)$.

\section{FACTORS AFFECTING DRIVING SIMULATOR} PERFORMANCE

Three logistic regression analyses were performed to investigate the factors associated with poor performance on the driving simulator (tracking error, reaction time, and number of off-road events per hour). In all cases driving experience (age when passed test, whether professional driver or not, and miles driven per year), alcohol, coffee intake, whether sleeping tablets were taken, patient characteristics (age, sex, shift worker), sleep study results (RDI), self-reported sleepiness (Epworth score), and history of adverse driving events were entered into the equation.
TRACKING ERROR

Table 2 shows the significant variables when tracking error was the dependent variable. After deletion of 10 cases with missing values, 140 subjects were analysed. According to the Wald criterion, reported alcohol intake, older age, sex (female), and near miss events in the previous 3 years were significantly associated with poor tracking error on the driving simulator. Using this model, $94.5 \%$ of those who had a poor tracking ability could be correctly classified, but only $15.9 \%$ of those with good tracking ability were correctly classified. The overall classification was $77.9 \%$. This indicates that tracking error was influenced by several factors which are mainly patient characteristics unrelated to OSA; however, history of a near miss event made a significant contribution.

NUMBER OF OFF-ROAD EVENTS PER HOUR

Table 3 shows the significant variables when the number of off-road events was the dependent variable. After deletion of nine cases because of missing data, 141 subjects were analysed. According to the Wald criterion, sex (female), older age, and history of near miss accidents were significantly associated with a higher number of off-road events on a driving simulator; $70.9 \%$ of patients with more than 10 off-road events/hour could be correctly classified using the model and $67.7 \%$ of those with less than 10 off-road events/hour were correctly classified. The overall classification was $69.5 \%$. This result again indicates that poor performance on the simulator is multifactorial, but a history of adverse driving events plays a significant role.

REACTION TIME

The third analysis attempted to investigate those who will perform badly in terms of reaction time. On this occasion only age was independently associated $(\mathrm{p}<0.01$, odds ratio $(\mathrm{OR})$ $1.04,95 \%$ confidence intervals (CI) 1.01 to 1.08).

CAN ADVERSE DRIVING EVENTS BE IDENTIFIED? A hierarchical logistic regression analysis was performed to determine whether information available from the patient, together with data obtained from the driving simulator, could be used to identify adverse driving events. Patient age, alcohol consumption, and sex were entered first because these appeared to influence driving simulator performance from the initial analysis. Once these factors were controlled for, the additional predictive power of driving simulator performance (tracking error, reaction time, and off-road events per hour) and OSA severity (RDI and Epworth score) were examined. According to the Wald criterion, the number of off-road events per hour on the simulator predicted the reported number of accidents in the previous year (table 4). Using this model, $100 \%$ of patients who did not have an accident were correctly classified but only $10 \%$ of those who did have an accident could be correctly classified. The Epworth score was associated with falling asleep at the wheel 
Table 5 Logistic regression analysis for nodding off at the wheel in the last 3 years

\begin{tabular}{lllllll}
\hline Variable & $B$ & Wald test & p value & Odds ratio & $\begin{array}{l}\text { Lower } \\
95 \% \text { CI }\end{array}$ & $\begin{array}{l}\text { Upper } \\
95 \% \text { CI }\end{array}$ \\
\hline Epworth score & 0.19 & 22.6 & $<0.00001$ & 1.21 & 1.12 & 1.31 \\
RDI & 0.001 & 0.012 & $>0.05$ & 1.001 & 0.98 & 1.02 \\
Tracking error & 0.13 & 0.43 & $>0.05$ & 1.14 & 0.77 & 1.69 \\
Reaction time & 0.04 & 0.11 & $>0.05$ & 1.05 & 0.80 & 1.38 \\
Off-road events/h & 0.0008 & 0.04 & $>0.05$ & 1.0008 & 0.99 & 1.001 \\
\hline
\end{tabular}

$\mathrm{RDI}=$ respiratory disturbance index.

${ }^{\star}$ OR for every 1 unit increase in variable (i.e. estimated risk of nodding off at the wheel increases by 1.21 for every increase in Epworth score by 1 )

Table 6 Logistic regression analysis for near miss accidents in the last 3 years

\begin{tabular}{lllllll}
\hline Variable & $B$ & Wald test & p value & $\begin{array}{l}\text { Odds } \\
\text { ratio }\end{array}$ & $\begin{array}{l}\text { Lower } \\
95 \% C I\end{array}$ & $\begin{array}{l}\text { Upper } 95 \% \\
\text { CI }\end{array}$ \\
\hline Epworth score & 0.14 & 14.88 & $<0.0001$ & 1.15 & 1.07 & 1.23 \\
RDI & 0.014 & 2.00 & $>0.05$ & 1.01 & 0.99 & 1.03 \\
Tracking error & 0.33 & 2.56 & $>0.05$ & 1.40 & 0.93 & 2.12 \\
Reaction time & 0.11 & 0.74 & $>0.05$ & 1.12 & 0.87 & 1.44 \\
Off-road events/h & 0.003 & 0.56 & $>0.05$ & 1.003 & 0.99 & 1.01 \\
\hline
\end{tabular}

$\mathrm{RDI}=$ respiratory disturbance index.

${ }^{\star} \mathrm{OR}$ for every 1 unit increase in variable (i.e. estimated risk of near miss accident increases by 1.15 for every increase in Epworth score by 1).

(table 5) and near miss accidents in the previous 3 years (table 6). No other factors were significantly associated with adverse driving events.

\section{Discussion}

This study shows that performance on a driving simulator is influenced by a number of factors. Those not directly related to on-road driving or OSA (age, female sex, and admitted alcohol consumption) have the strongest influence, but a history of near miss accidents is an independent predictor of a poor tracking error and number of off-road events per hour on the simulator.

The fact that performance on a simple simulator is affected by factors which are not directly related to driving history may explain the lack of relationship between simulator performance (using a steer clear vigilance test) and accident history in a previous study. ${ }^{8}$ Patients may perform poorly on the simulator simply because of a lack of ability to participate in a "computer game" irrespective of their ability to drive; older subjects performed less well and it is perhaps not surprising that they have less familiarity and confidence in the use of computers and electronic "games". Patients who admitted to a higher weekly consumption of alcohol also performed less well and they are more likely to have had a drink prior to attending for their study. The reason why women perform less well is not clear, since other studies suggest they perform better at tasks involving hand/eye coordination. ${ }^{29-31}$

However, despite these limitations, performance on the driving simulator did show some relationship to accident history. After controlling for confounding factors, data derived from the simulator still showed a relationship with accidents in the previous year. Patients who performed well on the simulator were unlikely to have had an accident in the previous year but there was no relationship between those who performed poorly and accident history. None of the patients with fewer than 10 off-road events/hour on the simulator reported having an accident in the previous year whereas only $10 \%$ of patients with more than 10 off-road events per hour on the simulator reported an accident in the previous year. Self-reported sleepiness (Epworth score) was associated with near misses and episodes of falling asleep at the wheel in the previous 3 years. OSA severity (RDI) was not associated with either adverse driving events or driving simulator performance, confirming the observation in other studies that classical indicators of severity are in fact poor indicators of the impact of OSA. ${ }^{8}$ Although, as a group, patients with OSA have been found to perform less well than matched controls on a simulator, there is a considerable overlap which confirms that other factors are important. ${ }^{8}{ }^{18-202527}$ We also found that there was no correlation between severity of OSA (RDI and Epworth score) and simulator performance. Most patients attending sleep clinics are middle aged men and therefore, because increasing age and female sex were independently associated with poor simulator performance, we performed a further analysis excluding these subjects. Unfortunately, this did not make a difference to the utility of the model.

There are several limitations to our methodology. Firstly, although we endeavoured to study consecutive patients, a large number of patients refused to take part which may have introduced a selection bias. Patients who thought they were safe drivers or those who felt more confident performing computer based tasks (for example, younger patients) may have been more likely to agree to participate in the study. Those who thought they had a problem with driving may have been reluctant to take part for fear of losing their licence, although they were told that the data derived from either the questionnaire or the simulator would not be used to advise on their safety to drive or become part of their medical records. However, the study group was not significantly different from the total population attending for sleep studies over the same period in terms of demographic, clinical, and sleep study data. The fact that $39 \%$ of patients refused to participate confirms that this is a sensitive issue and may limit the usefulness of simulators in routine practice.

Secondly, we relied on a questionnaire to obtain information about driving history and accidents, thus potentially introducing recall bias. It has been shown that patients with OSA are reluctant to report accidents ${ }^{32}$ and may under report symptoms. ${ }^{33}$ While this is a limitation, information from police, vehicle licensing authorities, or insurers may also underestimate the problem because not all accidents are reported and no information would have been available on near misses or episodes of falling asleep at the wheel, which have been found to be more likely in snorers with breathing pauses. ${ }^{3}$

Thirdly, our patients had one 5 minute practice run on the simulator which may not have been sufficient to accustom them to its use. One study ${ }^{27}$ has suggested that at least three 5 
minute practice runs are required to abolish any learning effect on the simulator, whereas others have used practice times ranging from 1 to 12 minutes. ${ }^{14}{ }^{25}$ It was felt that a longer practice run may have further reduced recruitment into the study and limited the applicability of its use in routine clinical practice in the future. One single 5 minute practice run, as recommended by the supplier of the simulator, was therefore performed by all subjects.

Fourthly, we only tested patients for $20 \mathrm{~min}$ utes whereas actual driving is often for much longer periods; furthermore, the circumstances of the simulator reproduce motorway driving whereas accidents also happen on quiet rural roads or in close proximity to home.

Finally, all the analyses used accidents which had already occurred and this makes the assumption that what happened in the past will occur again in the future.

Limited sleep studies, using either the Densa DMS2000 or the Autoset Clinical 1, were used to establish the diagnosis of OSA and assess its severity (RDI). Studies have shown the sensitivity and specificity of the Densa to be $82 \%$ and $90 \%$ for the diagnosis of $\mathrm{OSA}^{34}$ and of the Autoset to be $100 \%$ and $92 \% .{ }^{35}$ However, both machines underscored hypopnoeas when compared with full polysomnography, so we may have underestimated the degree of mild OSA in terms of RDI in this study. However, the poor correlation between RDI, accident history, and simulator performance suggests that the addition of EEG monitoring would not have significantly altered the results. Furthermore, a recent meta-analysis of diagnostic tools in sleep apnoea failed to recommend standardisation of methodology ${ }^{36}$ and limited studies appeared to be most useful when investigating OSA. A further study by Douglas et $a b^{\beta 7}$ concluded that recording sleep was of no diagnostic value, and that OSA could be defined as accurately using RDI expressed as time in bed as RDI expressed as time asleep.

Physicians treating patients with OSA need to advise their patients about driving. Current UK driving regulations state that patients with OSA and hypersomnolence should not drive. However, not all patients with OSA are at increased risk of RTA and there is no link with disease severity. Adopting a policy of advising all patients not to drive may have far reaching implications on their lifestyles and livelihoods. It may also prevent patients admitting that they have a problem and stop them seeking help and therefore treatment. Our results confirm that it is difficult to determine whether an individual is safe to drive. Those who do not report daytime sleepiness and do not have more than 10 off-road events/hour on the driving simulator appear to be at least risk. Poor performance on the simulator, however, does not indicate that the patient is not safe to drive. These data need to be confirmed in further studies before simple computer simulators can be used in clinical practice to advise whether or not an individual is safe to drive.
Dr M Sircar was funded by the Raj Nanda Pulmonary Disease Research Trust.

There are no conflicts of interest.

1 Young T, Palta M, Dempsey J, et al. The occurrence of sleep disordered breathing among middle aged adults. $N$ Engl $\mathcal{F}$ Med 1993;328:1230-5

2 Stradling JR, Crosby JH. Predictors and prevalence of obstructive sleep apnoea and snoring in 1001 middle aged men. Thorax 1991:46:85-90.

3 Ohayon MM, Guilleminault C, Priest RG, et al. Snoring and breathing pauses during sleep; telephone interview survey of a United Kingdom population sample. BMF 1997;314: $860-3$

4 Wu H, Yan-Go F. Self-reported automobile accidents involving patients with obstructive sleep apnea. Neurology 1996;46:1254-7.

5 Findley LJ, Unverzagt ME, Suratt PM. Automobile accidents involving patients with obstructive sleep apnea. Am Rev Respir Dis 1988;138:337-40.

6 Haraldsson PO, Carenfelt C, Diderichsen F, et al. Clinical symptoms of sleep apnea syndrome and automobile accidents. ORL F Otorhinolaryngol Relat Spec 1990;52:5762

7 Aldrich MS. Automobile accidents in patients with sleep disorders. Sleep 1989;12:487-94.

8 Barbe F, Pericas J, Munoz A, et al. Automobile accidents in patients with sleep apnea syndrome. An epidemiological patients with sleep apnea syndrome. An epidemiological and mechanistic

9 Noda A, Yagi T, Yokota M, et al. Daytime sleepiness and automobile accidents in patients with obstructive sleep apnea syndrome. Psychiatry Clin Neurosci 1998;52:221-2.

10 Stradling JR, Crosby JH, Payne CD. Self reported snoring and daytime sleepiness in men aged 35-65 years. Thorax 1991;46:807-10.

11 Engleman HM, Asgari-Jirhandeh N, McLeod AL, et al. Self-reported use of CPAP and benefits of CPAP therapy: a patient survey . Chest 1996;109:1470-6.

12 George CF, Smiley A. Sleep apnea and automobile crashes. Sleep 1999;22:790-5

13 Findley LJ, Fabrizio M, Thommi G, et al. Severity of sleep apnea and automobile crashes. $N$ Engl f Med 1989;320: $868-9$.

14 Findley L, Unverzagt M, Guchu R, et al. Vigilance and automobile accidents in patients with sleep apnea or narcolepsy. Chest 1995;108:619-24.

15 Teran-Santos J, Jimenez-Gomez A, Cordero-Guevara J. The association between sleep apnoea and the risk of traffic accidents. N Engl f Med 1999;340:847-51.

16 George CF, Boudreau AC, Smiley A. Comparison of simulated driving performance in narcolepsy and sleep apnea patients. Sleep 1996;19:711-7.

17 Young T, Blustein J, Finn L, et al. Sleep-disordered breathing and motor vehicle accidents in a population- based sample of employed adults. Sleep 1997;20:608-13.

18 George CFP, Boudreau AC, Smiley A. Simulated driving performance in patients with obstructive sleep apnoea. Am 7 Respir Crit Care Med 1996;154:175-81.

19 Findley LJ, Suratt PM, Dinges DF. Time-on-task decrements in "steer clear" performance of patients with sleep ments in "steer clear" performance of patients

20 Findley LJ, Fabrizio MJ, Knight $\mathrm{H}$, et al. Driving simulator performance in patients with sleep apnea. Am Rev Respir Derformance in patients

21 Risser M, Ware JC, Freeman F. Driving simulation with EEG monitoring in normal and obstructive sleep apnoea patients. Thorax 2000;23:393-8.

22 George CFP, Boudreau AC, Smiley A. Effects of nasal CPAP on simulated driving performance in patients with obstructive sleep apnoea. Thorax 1997;52:648-53.

23 Haraldsson PO, Carenfelt C, Lysdahl M, et al. Does uvulopalatopharyngoplasty inhibit automobile accidents? Laryngoscope 1995;105:657-61.

24 Engleman HM, Martin SE, Deary IJ, et al. Effect of continuous positive airway pressure treatment on daytime function in sleep apnoea/hypopnoea syndrome. Lancet 1994;343:572-5.

25 Hack M, Davies RJ, Mullins R, et al. Randomised prospective parallel trial of therapeutic versus subtherapeutic nasal continuous positive airway pressure on simulated steering performance in patients with obstructive sleep apnoea. performance in patients

26 Johns MW. A new method for measuring daytime sleepiness: the Epworth sleepiness scale. Sleep 1991;14: $540-5$

27 Juniper M, Hack MA, George CF, et al. Steering simulation performance in patients with obstructive sleep apnoea and matched control subjects. Eur Respir f 2000;15:590-5.

28 Davies RJ, Crosby J, Vardi-Visy K, et al. Non-invasive beat to beat arterial blood pressure during non-REM sleep in obstructive sleep apnoea and snoring. Thorax 1994;49: 335-9.

29 Wait JS, Welch RB, Thurgate JK, et al. Drinking history and sex of subject in the effects of alcohol on perception and perceptual-motor coordination. Int $f$ Addict 1982;17:44562 .

30 Harris CJ, Herbert M, Steele RJ. Psychomotor skills of surgical trainees compared with those of different medical specialists. Br F Surg 1994;81:382-3. 
31 Schueneman AL, Pickleman J, Freeark RJ. Age, gender, lateral dominance, and prediction of operative skill among general surgery residents. Surgery 1985;98:506-15.

32 Findley L, Smith C, Hooper J, et al. Treatment with nasal CPAP decreases automobile accidents in patients with sleep apnea. Am F Respir Crit Care Med 2000;161:857-9.

33 Engleman HM, Hirst WS, Douglas NJ. Under reporting of sleepiness and driving impairment in patients with sleep apnoea/hypopnoea syndrome. F Sleep Res 1997;6:272-5.

34 Lloberes P, Montserrat JM, Ascaso A, et al. Comparison of partially attended night time respiratory recordings and full polysomnography in patients with suspected sleep apnoea/

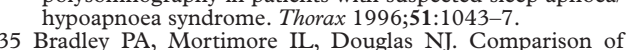
polysomnography with ResCare Autoset in the diagnosis of the sleep apnoea/hypopnoea syndrome. Thorax 1995;50: $1201-3$.

36 Ross SD, Sheinhait IA, Harrison KJ, et al. Systematic review and meta-analysis of the literature regarding the diagnosis of sleep apnea. Sleep 2000;23:519-32.

37 Douglas NJ, Thomas S, Jan MA. Clinical value of polysomnography. Lancet 1992;339:347-50. 